\title{
VIOLÊNCIA DOMÉSTICA CONTRA A MULHER: REALIDADES E
} REPRESENTAÇÕES SOCIAIS

\author{
DOMESTIC VIOLENCE AGAINST WOMEN: REALITIES AND SOCIAL \\ REPRESENTATIONS
}

\author{
Denire Holanda da Fonseca, Cristiane Galvão Ribeiro e Noêmia Soares Barbosa Leal \\ Centro Universitário de João Pessoa, João Pessoa, Brasil
}

\section{RESUMO}

Este estudo buscou verificar representações sociais das mulheres que sofrem ou sofreram algum tipo de violência de seus companheiros, buscando entender a subjetivação desse fenômeno, como também verificar os principais prejuízos nas esferas sociais, psicológicas e ocupacionais dessas mulheres. 12 participantes responderam a entrevista semiestruturada, e foram feitas análises de conteúdo de Bardin (2002) e ancoradas na Teoria das Representações Sociais de Moscovici. Como resultado foi constatado que a maior prevalência é a violência psicológica, causando danos emocionais a longo prazo, trazendo sérios prejuízos nas esferas do desenvolvimento e da saúde psicológica da mulher. Verificou-se também que o ciclo de violência é alimentado pela tolerância e autoculpa e pela má compreensão da mesma. Propõem-se outros estudos nesta esfera com finalidade de maior compreensão do fenômeno da violência contra as mulheres.

Palavras-chave: violência doméstica; mulheres; representações sociais.

\begin{abstract}
The objective of this study is to verify the social representations of women who suffer or have suffered some kind of violence from their partners, trying to considerate the subjectivity of this phenomenon, and also identify the main harms in the social, psychological and occupational spheres of these women. Twelve participants have answered to semi structured interviews, and a analysis of Bardin (2002) contents were made based in Theory of Social Representation of Moscovici. As results, it was observed that most cases are counted in forms of psychological violence -which cause emotional suffering in long term and bring serious damages in aspects of self-development and psychological health of the victims. It was also noticed that the cycle of violence is fed by tolerance and self-blame that the misunderstood of their situation implicate. It is proposed further studies in this area with the purpose to understand better the phenomenon of violence against women.
\end{abstract}

Keywords: domestic violence; women; social representations.

Este estudo delineou-se com a finalidade de conhecer as Representações Sociais de mulheres vítimas de violência doméstica. Além disso, buscou-se compreender como o fenômeno é interiorizado e como a violência sofrida afeta e interfere em suas vidas nas esferas do convívio social, saúde psicológica, qualidade de vida e ocupação profissional.

A Teoria das Representações Sociais é caracterizada como um conjunto de explicações, crenças e ideias que permitem evocar um dado acontecimento, pessoa ou objeto. Essas representações são resultantes da interação social, pelo que são comuns a um determinado grupo de indivíduos (Moscovici, 2003). É relevante conhecer as representações sociais das mulheres vítimas de violência doméstica e verificar como este conhecimento, elaborado e partilhado por este grupo de pertença, cria uma realidade prática e cotidiana. Faz-se necessário conceber as mulheres vítimas de violência como sujeitos sociais que carregam em si as características culturais do gênero que, segundo Ribeiro e Coutinho (2011), é uma construção social, e tem colocado o homem numa situação de dominação sobre a mulher ao longo da história.

A Organização Mundial de Saúde (OMS) divulgou em 2002 um relatório intitulado "Relatório Mundial sobre Violência e Saúde". Neste relatório, a violência é conceituada como "o uso intencional da força física ou do poder, real ou ameaça, contra si próprio, contra outra pessoa, ou contra um grupo ou uma comunidade, que resulte ou tenha grande possibilidade de resultar em lesão, morte, dano psicológico, deficiência de desenvol- 
vimento ou privação" (Zuma, 2005, p. 2). De acordo com o autor, a partir dessa definição, a violência pode ser dividida em três categorias: violência autoinfligida, violência interpessoal e violência coletiva. Cada uma delas contendo subtipos. A violência que ocorre nas relações familiares é um subtipo da violência interpessoal e, por sua vez, é dividida em violência entre parceiros íntimos.

Segundo estudo da Organização das Nações Unidas (ONU) de 2006, "violência contra a mulher" é todo ato de violência praticado por motivos de gênero, dirigido contra uma mulher (Gadoni-Costa \& Dell'Aglio, 2010, p. 152). Alguns estudiosos concordam que esse tipo de violência sempre existiu, associada a vários fatores, principalmente a questões de gênero.

Ao focar esta interface, depara-se com amplas implicações ligadas ao fenômeno. A maioria das vítimas permanece coagida a um relacionamento baseado, muitas vezes, na dependência financeira e emocional, levando a eventos cíclicos de violência. Na maior parte dos casos, a violência foi cometida pelo próprio parceiro, na residência (Côrtes, 2012).

A condição de violência é, antes de tudo, uma questão de violação dos direitos humanos. Pode estar associada a problemas variados, complexos e de natureza distinta. Também pode estar atrelada a questões conceituais referentes à distinção entre: poder e coação; vontade consciente e impulso; determinismo e liberdade. A violência contra a mulher é um fenômeno multicausal, multidimensional, multifacetado e intransparente (Pequeno, 2007).

A própria Lei $\mathrm{n}^{\circ} 11.340$, que rege os mecanismos para coibir a violência doméstica e familiar contra a mulher (2006), define os tipos de violência, delimitando cinco domínios, a saber: físico, patrimonial, sexual, moral e psicológico. A Violência física implica ferir e causar danos ao corpo e é caracterizada por tapas, empurrões, chutes, murros, perfurações, queimaduras, tiros, dentre outros; Violência patrimonial refere-se à destruição de bens materiais, objetos, documentos de outrem; Violência sexual, entre outros tipos de manifestação, ocorre quando o agressor obriga a vítima, por meio de conduta que a constranja, a presenciar, manter ou a participar de relação sexual não desejada; Violência moral constitui qualquer conduta que caracterize calúnia, difamação ou injúria e a Violência psicológica ou emocional é a mais silenciosa, deixando marcas profundas, por não ter um caráter momentâneo e ter efeito cumulativo, sendo caracterizada por qualquer conduta que resulte em dano emocional como a diminuição da autoestima, coação, humilhações, imposições, jogos de poder, desvalorização, xingamentos, gritos, desprezo, desrespeito, enfim, todas as ações que caracterizem transgressão dos valores morais.
A violência doméstica contra a mulher atinge repercursões em vários aspectos da sua vida, no trabalho, nas relações sociais e na saúde (física e psicológica). Segundo o Banco Mundial (Ribeiro \& Coutinho, 2011), um em cada cinco dias de falta ao trabalho é causado pela violência sofrida pelas mulheres dentro de suas casas; a cada cinco anos, a mulher perde um ano de vida saudável se ela sofre violência doméstica; na América Latina, a violência doméstica atinge entre $25 \%$ a $50 \%$ das mulheres; uma mulher que sofre violência doméstica geralmente ganha menos do que aquela que não vive em situação de violência; estima-se que o custo da violência doméstica oscila entre $1,6 \%$ e $2 \%$ do PIB de um país, fatos esses que demonstram que a violência contra a mulher sai do âmbito familiar e atinge a sociedade como um todo, configurando-se em fator que desestrutura o tecido social.

Em alguns países o percentual de mulheres que afirmam terem sido agredidas fisicamente por um homem chegou a 50\%. As estatísticas da Fundação Perseu Abramo, em relação à pesquisa realizada em 2001, informa que a cada 15 segundos uma mulher é agredida no Brasil e mais de 2 milhões de mulheres são espancadas a cada ano por seus maridos ou namorados, atuais e antigos.

Os problemas ligados à saúde também emergem em grande proporção; desde a década de 80 que a Organização Mundial de Saúde (OMS) considera assunto de saúde pública pela sua dimensão e pela gravidade das sequelas orgânicas e emocionais que produz (Alves \& Coura Filho, 2001).

A literatura é vasta em descrever as dimensões da violência e suas possíveis consequências para a saúde e o bem-estar. Pesquisas correlacionam à violência distúrbios gastrointestinais, lesões, doenças sexualmente transmissíveis, gravidez não desejada, sentimento de culpa, baixa autoestima, depressão, ansiedade, suicídios (Oliveira et al., 2005; Villela, 2008). Relatos da Organização Pan-Americana de Saúse (OPAS) referentes a uma pesquisa realizada em 2003 informam que as pessoas que vivem em contexto violento, que tende à volência, também se encontram em maior risco de sofrer desordens alimentares, alcoolismo e abuso de outras drogas, estresse pós-traumático, depressão, ansiedade, fobias, pânico e baixa autoestima.

Muitas são as implicações envolvendo o fenômeno da violência doméstica contra a mulher, com a repercussão de casos nos meios de comunicação e atingindo a sociedade de uma maneira geral, a ponto de ter sido criada e sancionada uma lei visando a coibir a violência contra as mulheres, caso da Lei $\mathrm{n}^{\circ} 11.340$, de 7 de agosto de 2006 (Lei Maria da Penha). Dentre muitos aspectos, essa Lei apontou a criação de delegacias especializadas e unidades de apoio à mulher vítima 
e a seus filhos, bem como punições mais rigorosas aos homens agressores.

Nos dias atuais o Brasil possui mais de 300 delegacias especializadas, em quase todos os estados (Debert \& Oliveira, 2007). As delegacias têm diversas denominações: Delegacia de Defesa da Mulher (DDM), Delegacia para a Mulher (DM), Delegacia Especializada no Atendimento à Mulher (DEAM). Essas instituições se tornaram de grande importância, pois através do trabalho multidisciplinar de vários profissionais, aliados a implementações de políticas públicas, tem sido empenhado esforços no intuito de prevenir e erradicar o fenômeno da violência contra a mulher (Sagot, 2007; Schraiber et al., 2007).

As informações contidas neste estudo foram buscadas na Delegacia Especializada no Atendimento à Mulher (DEAM) no município de João Pessoa, Estado da Paraíba. Além das premissas aqui propostas, este trabalho pretendeu com a comunidade acadêmica e científica.

\section{Metodologia}

Modelo de estudo delimitado como estudo de campo, do tipo descritivo, abordagem qualitativa. Foi considerada uma amostra não probabilística por conveniência, com 12 mulheres com idade iguais ou maiores a 18 anos, que buscaram a Delegacia Especializada no Atendimento à Mulher na cidade de João Pessoa durante o período de coleta de dados das pesquisadoras. Não houve critérios para inclusão referente a situações como condição socioeconômica ou grau de escolaridade, apenas foram considerados que as participantes estivessem passando ou já tivessem passado por episódios de violência conjugal de quaisquer tipos e que residissem na cidade de João Pessoa. Os critérios para exclusão foram: situações em que a mulher procurou a Delegacia por outros motivos que não os de violência conjugal ou a qualquer momento se recusar a assinar o
Termo de Consentimento Livre e Esclarecido (TCLE). O Projeto de Pesquisa foi aprovado pelo Comitê de Ética da Secretaria de Estado da Saúde da Paraíba, trâmites $n^{\circ} 196 \mid 96$. A coleta de dados ocorreu entre março e abril de 2010. O instrumento utilizado para a coleta foi uma entrevista semiestruturada contendo cinco perguntas, as quais propunham verificar como as participantes entendiam a violência, como viam o agressor, as causas e consequências, dentre outros aspectos. Os resultados foram analisados por meio de estudo de conteúdo temático (Bardin, 2002); e baseados no estudo das Representações Sociais de Moscovici (2003), para quem o objeto de investigação são elementos da realidade social, são modos de conhecimentos, saberes do senso comum que surgem e se legitimam na conversação interpessoal. Sugere que se intercale a escuta do material gravado com a leitura do material escrito, de forma que se assimilem informações que permitam compreender a emergência dos investimentos afetivos. Após o esclarecimento dos objetivos do estudo, cada participante assinou o TCLE. Esclarecidas sobre a gravação das entrevistas, todas concordaram com o procedimento e foram informadas que ficariam livres para falarem sobre a questão da forma que melhor lhes ocorresse. As entrevistas se deram em local reservado garantindo o sigilo das informações. Este estudo foi realizado observando os aspectos éticos para pesquisas com seres humanos descritos como consta na resolução art.196/96, tendo sido observadas criteriosamente suas proposições.

\section{Resultados e discussões}

Os resultados estão apresentados na forma de tópicos e desenvolvidos a seguir. A análise gerou um conhecimento classificado em sete categorias e vinte e cinco subcategorias de acordo com a demonstração na Tabela 1.

Tabela 1

CATEGORIAS

1- TIPOS DE VIOLÊNCIA

2- REPRESENTAÇÃO DA VIOLÊNCIA

3- MANIFESTAÇÕES DA MULHER
SUBCATEGORIAS

1.1 Física

1.2 Psicológica

2.1 Depreciativa

2.2 Frequente

2.3 Desarmônica

3.1 Passividade

3.2 Vergonha

3.3 Decepção

3.4 Culpa

3.5 Sofrimento 


\begin{tabular}{|c|c|}
\hline 4- PERCEPÇÃO DO AGRESSOR & $\begin{array}{l}\text { 4.1 Agressivo } \\
\text { 4.2 Dupla personalidade/doente } \\
\text { 4.3 Incorrigível } \\
\text { 4.4 Digno de pena }\end{array}$ \\
\hline 5- MOTIVAÇÕES DA VIOLÊNCIA & $\begin{array}{l}\text { 5.1 Ciúme } \\
\text { 5.2 Poder } \\
\text { 5.3 Histórico familiar }\end{array}$ \\
\hline 6- CONSEQUÊNCIAS DA VIOLÊNCIA & $\begin{array}{l}\text { 6.1 Trauma } \\
\text { 6.2 Desamor } \\
\text { 6.3 Insensibilidade }\end{array}$ \\
\hline 7- PERSPECTIVAS PARA O FUTURO & $\begin{array}{l}\text { 7.1 Esperança de mudança do agressor } \\
\text { 7.2 Realização pessoal } \\
\text { 7.3 Sair do ciclo da violência } \\
\text { 7.4 Dedicação materna }\end{array}$ \\
\hline
\end{tabular}

\section{Tipos de violência}

Foi constatado que a violência psicológica ou emocional e a violência física são as mais frequentes. $\mathrm{Na}$ maioria dos casos, a violência psicológica ou emocional é a mais encontrada, principalmente nas modalidades de humilhações, xingamentos e desprezo.

Esse tipo de violência ocorre primariamente, e perdura durante todo o ciclo de violência; somando-se a essa, com o passar do tempo outras formas de violência vão sendo incorporadas. Dessa forma, a violência psicológica ocorre sempre a priori. Observa-se nas vítimas sofrimento psíquico, segundo elas mais intenso do que a violência na forma de agressão física. Admitem seu caráter silencioso, crônico, comprometedor da saúde psicológica da mulher.

Eu sofro constantemente/O meu marido me agride com palavrões/Ele humilha/Ele xinga/Dizia que eu era feia,obesa,idiota,imprestável/ Me chamava de merda/ Ele diz que eu só sirvo pra limpar chão/ Que eu sou feia, horrorosa/Que arranja mulher mais bonita do que eu/ Eu me sinto um nada, um lixo,com baixa autoestima.

Os recortes acima citados trazem a violência psicológica ou emocional sofrida por muitas mulheres, por vezes durante anos, causando intenso sofrimento psíquico. O companheiro usa esse tipo de agressão na intenção de denegrir a imagem da mulher, fazendo-a sentir-se sem valor e desprezada. É um fenômeno de enlaces psíquicos, que faz com que a mulher perca, com o passar do tempo, dentre outras coisas, sua autoestima, o que confirmam Monteiro e Souza (2007) ao afirmarem a prevalência desta modalidade de violência sobre outros tipos. Dessa forma, a violência cometida por homens contra mulheres assume uma feição crônica e estabilizada; é empreendida sobre a mesma vítima, é constantemente ritualizada. A literatura traz a prevalência da violência psicológica ou emocional sobre outros tipos de violência (Monteiro \& Souza, 2007).
O sofrimento psíquico e seu efeito cumulativo podem vir a desenvolver doenças psicossomáticas variadas; a depressão, por exemplo, é a mais comum. A depressão é uma doença altamente prevalente na atualidade. Especialistas afirmam que até 2020 será a doença mais incapacitante do mundo (Medeiros \& Sougey, 2010). Dentre os fatores citados como psicodinâmicos desencadeadores da depressão estão os eventos estressores do ambiente familiar. A violência psicológica compromete a autoestima, levando à distorção do pensamento na construção de crenças de desvalor e autodepreciação, interferindo no bem-estar e no desenvolvimento da saúde psicológica da mulher, como nas unidades temáticas abaixo citadas:

Ela só trouxe pontos negativos pro meu psicológico principalmentel A gente fica abatida/E a pessoa fica assim sem se dá valor, assim... Sei lá... /.

Os maus-tratos sofridos pela mulher geram perdas significativas em sua saúde física e mental (Monteiro $\&$ Souza, 2007). As repercussões na vida da mulher violentada são enormes. O Ministério da Saúde vem, ao longo dos anos, implementando políticas e normatizando ações de prevenção e tratamento dos agravos decorrentes da violência contra as mulheres, uma vez que são agravos de alta frequência e que causam sérias repercussões ao estado físico, psíquico e social, sendo determinantes no processo de saúde e adoecimento das pessoas (Januário et al., 2010).

\section{Representações da violência}

As mulheres objetivam a violência sofrida como inexplicável, destruindo a harmonia do casal e a convivência familiar, além da frequência com que ocorre, estando associada a sentimentos como tristeza, medo, preocupação e sentimentos de impotência.

Representa tristeza/ medo, preocupação pela situação que eu nunca pensei passar na minha vida/ Tudo 
de ruim/Geralmente, é quase todo dia pra falar a verdade/A violência só não acontecia se eu não tivesse em casa, para falar a verdadel A violência representa muita coisa/ eu penso em ir embora para outro lugar/ sei não viu/.

Ao representar a ação violenta, as vítimas apontam que não há justificativa, é inexplicável, "Não tem justificativa para violência", afirmando que depois de começarem os maus-tratos, qualquer atitude ou palavra dispensada inicia o evento de agressão. Muitas vezes quando percebem já estão sendo agredidas sem saber o porquê, citam ainda que os companheiros apenas adquiriram o hábito de bater ou humilhar. A violência arrasa o relacionamento "Ela vem para acabar com tudo/ Qualquer tipo de harmonia acaba/". Os sentimentos ligados à representação da violência são negativos e depreciativos. Com a harmonia destruída, o casal passa a não ter mais qualidade na relação, que começa a ser desgastante e perigosa. Uma vez iniciada, tornam-se constante as brigas e discussões. Foi relatado que a violência ocorre quase que diariamente.

\section{Manifestações da mulher diante da violência}

De acordo com Soares (2004), muitas vezes uma mulher em situação de violência se sente especialmente amedrontada e envergonhada por não conseguir se fazer ouvir e respeitar por seu agressor, gerando sentimentos de impotência. A maneira como suas reações são manifestas advém da própria relação com o companheiro. Neste estudo, as principais manifestações apresentadas foram de passividade, vergonha, decepção, culpa e sofrimento. E, dentre essas, notou-se a decepção como mais frequente. Muitas mulheres simbolizam a imagem do casamento perfeito e feliz em seus sonhos, com a esperança constantemente renovada de que o agressor vai mudar, que as coisas vão melhorar e que "tudo um dia vai passar como num passe de mágica", sentimento esse que também é, segundo elas, frequentemente desfeito pelas decepções em contato com a realidade do comportamento do companheiro. Perdura no relacionamento o misto de esperança e decepção, fazendo com que o desgaste se acentue.

A pessoa fica assim, sem saber o que fazer/ Porque a pessoa está ali com você direto, e você não espera/ Ter passado esses anos todos achando que vai melhorar, mas não melhoral Nem parece que é meu marido, porque no começo é um mar de rosas/ De repente mudou/Assim, eu fico com tristeza assim/ decepção sabe?/ Queria que voltasse a ser assim/.

A vergonha foi mais um sentimento amplamente descrito. As vítimas relataram que muitas vezes negam a situação, encobrem, escondem, não demonstram em público, ficam reclusas, não saem de casa, limitam-se socialmente restringindo as amizades, vivendo praticamente em condições de confinamento. Segundo Monteiro e Souza (2007), a indiferença com que são tratadas contribui para que elas permaneçam na inautenticidade.

Raiva/tenho raiva de quem sabe que eu estou deixando os outros me fazer assim/Eu sou muito envergonhada pela minha situação/

Foram também demonstrados sentimentos de culpa: "Às vezes eu sentia raiva de mim mesmo/ $O$ inimigo era eu/". Demonstram também os sofrimentos intensos diante desse misto conflituoso, da consciência de que algo está errado, mas percebem também que não possuem forças suficientes para atuar sobre ela, "Desespero/de tristeza/medo/Angústia". A culpa "Às vezes eu sentia raiva de mim mesma/ O inimigo era eu" também perdura com intenso sofrimento. "Desespero/tristeza/ medo/ Angústia" completam o quadro angustiante.

\section{Como a mulher percebe o agressor}

Importante constatar como as participantes percebem seus companheiros das formas mais contraditórias, variando entre "pessoa boa", "pessoa ótima", "muito simpática" até "covarde", "canalha" e "doente". O termo "doente" aparece em quase todas as falas, definindo seus companheiros como psicopatas, esquizofrênicos e com dupla personalidade.

Duas faces, duas pessoas em uma só/É horrivel lhe dar
com uma pessoa que é violenta, ignorante/ Direto bate
em você/ e na mesma hora está brincando muito/ Eu
considero ele um doente/ Então casei com um homem
que é um psicopata/ Não sei se ele tem um pouco de
psicopata, eu não sei nem descrever/ Eu acho que é
uma doença dele, pelas atitudes que ele toma/Ele é
esquizofrênico/ Ele age como uma pessoa que não é
normal entendeu?/

Para Goleman (2003), a racionalização é uma das estratégias mais comuns da negação dos verdadeiros motivos do sujeito, cobrindo e bloqueando o verdadeiro impulso que provocou o ato agressivo, substituindo-o por outro, inventado. Já para Dantas-Berger e Giffin (2005), uma ordem social de tradição patriarcal por muito tempo "consentiu" um certo padrão de violência contra as mulheres, designando ao homem o papel "ativo" na relação social e sexual entre os sexos, ao mesmo tempo em que restringiu a mulher à passividade e reprodução, demonstrando construções sociais que ancoraram as representações das mulheres deste estudo.

As mulheres entrevistadas demonstraram uma visão bastante interessante sobre seus companheiros, em contrapartida ao conceito de doença citado acima. Essas mulheres veem seus companheiros como simpáticos, brincalhões, pessoas boas e alegres: 
E eu vejo que uma boa pessoa boal Mas ele é uma ótima pessoa sabe/Eu vejo ele como uma pessoa muito simpática/ Ele é ótimo/ O vejo como uma pessoa simpática, alegre, extrovertida/.

Esta “confusão" perceptiva pode ser a explicação para o ciclo violento perdurar por anos. Uma vez que operam entre momentos alegres e tristes, estas mulheres se mantêm alimentando a violência por estarem sempre na espera dos momentos "gratificantes" do relacionamento, em contrapartida aos momentos de crise.

Observa-se, também, o medo, a falta de perspectiva de mudanças, sentimento de pena:

Tenho muito medo dele/ das ameaças/Eu me tornei uma pessoa medrosa, desconfiada de todos os homens/ Sempre ele me ameaça/ Já escondi até facão e o martelo, porque se ele encontrar quer logo me agredir. E ele é uma pessoa que eu acho que nunca vai mudar/ ele não vai mudar/ ele muda não/.Eu vejo que eu tenho pena dele/ Às vezes eu sinto pena que ele é assim/tenho muita pena sabe? /

E agressivo, canalha, covarde:

Ele é um canalha, covarde/ mas tem situação que ele fica muito agressivo/ e muito ignorante/muito nervoso/ e muito irritado/É horrivel lidar com uma pessoa que é violenta/ ignorantel.

Fica clara a demonstração de confusão nos relacionamentos amorosos que convivem com o fantasma da violência. As vítimas desenvolvem insegurança nos sentimentos demonstrados, uma vez que variam de um extremo a outro, podendo ser inferidas, dessas relações, questões relacionadas ao domínio da relação pelo homem (relações de poder), violência de gênero, em que se observam comportamentos de submissão, ingenuidade e vulnerabilidade. Saffioti (2001) traz que o espaço intrafamiliar não se configura como um campo homogêneo e harmônico, tendo em vista que as interações tecidas neste âmbito estão entrelaçadas e imbricadas em condicionamentos e normatizações marcadas por três contradições básicas: o gênero, a raça/ etnia e a classe social, que se mesclam e potencializam a configuração da violência doméstica. Carneiro (2003) ratifica essas implicações, afirmando que quanto mais sujeitas a esse conjunto de desigualdades, maiores são as possibilidades de as mulheres se tornarem vulneráveis à preservação de sua integridade física e emocional; ficando a condição mental fragilizada pelas "idas e vindas", pela esperança de mudança, sentimentos de pena e pelas agressões físicas e psicológicas.

\section{Causas e consequências da violência}

Dentre as principais causas para a violência, as mulheres citam:

\section{Ciúmes}

Quando você fala ou você ver ou olha pra qualquer lugar/ ele já pensa você está olhando para outra pessoa/ está dando em cima/ Vê com outra visão coisa que não existe/Ele é muito ciumento/

\section{Poder}

Coisas que eu só queria dividir com ele/ mas ele não escutava não/ a opinião dele que prevalência/ Isso já gerava uma discussão/ Principalmente à noite/ eu passava o dia sem falar com ele/ mas tinha que falar, alguma coisa tinha que pedir resolver/.

Histórico familiar

Deve ter sido pelo pai que também era violento/ e ele foi criado só pelo pai, deve bater na mãe também/ eu acho que isso vem da infância também/ eu acho que ele ficou com aquilo/ aquele costume/Como uma coisa que você está aprendendo, vai aprendendo/ o professor ensinando, e vai aprendendo/.

As causas da violência são descritas principalmente pelo ciúme e jogo de poder. Considerando-se a complexidade do problema, associada à questão da construção social dos papéis masculinos e femininos e da desigualdade existente nas relações de gênero segundo Galvão e Andrade (2004), seriam essas as causas mais comuns que geram a violência contra a mulher. O jogo de poder masculino advém dessas crenças de o homem possuir certos direitos e privilégios a mais do que as mulheres. Os ciúmes podem estar relacionados à possessividade: muitos homens tratam as mulheres como objeto de sua propriedade.

Os condicionamentos dominantes referentes a certas classificações e compreensões de violência, principalmente quando se trata de mulheres casadas ou em uniões estáveis, levam ao não reconhecimento da violência produzida na intimidade e na rotina de uma relação conjugal e à consequente aprovação dos atos abusivos cometidos pelos homens na posição de senhores e donos de suas mulheres (Almeida \& Bandeira, 2006).

As consequências da violência são numerosas. Dentre as mais compreendidas pelas mulheres, estão: trauma, desamor e insensibilidade:

Trauma

E por dentro, deixou muitas marcas/ $O$ amor que eu senti por ele, cada dia mais, está diminuindo/ Tudo de Ruim né? / Ela vem para destruir tudo/ Trouxe muitas consequências, pro meu psicológico principalmentel Representa muito dor, tudo de ruim/Eu me tornei uma pessoa muito medrosa/ Tenho medo dos homens/.

\section{Desamor}

O amor que eu senti por ele/ cada dia está diminuindo/ por falta de consideração que ele tem/ e as agressões que ele faz contra mim/ Tudo acaba/O amor acaba/ 


\section{Insensibilidade}

A pessoa se torna quase igual à outra pessoa/.Vai aprendendo/ Tanto aprende o que é bom e aprende o que é ruim, sabia?/ Aprende mesmo/

Percebe-se que as consequências da violência são todas danosas, como um todo, à saúde da mulher vítima de violência doméstica. Segundo Ribeiro e Coutinho (2011), a vivência da violência doméstica diminui drasticamente a qualidade de vida dessas mulheres, atingindo negativamente sua saúde física, psicológica e principalmente a social, fazendo as vítimas se isolarem cada vez mais, e perderem gradativamente sua rede de apoio, tornando-se vulneráveis e com poucas estratégias de enfrentamento, sendo cada vez mais difícil quebrar este ciclo.

Mulheres, parceiros, incidências e resistências no campo da violência de gênero parecem ser apenas alguns nós de uma rede de processos multidirecionais que, hoje, apresentam a violência como um problema público altamente complexo. No panorama geral, percebe-se a consequência em âmbitos sociais: a restrição do convívio social, má aceitação social, preconceito, descriminação.

\section{Perspectivas para o futuro}

A esperança de que o companheiro mude está representada como a principal expectativa das participantes. Outras, como realizações pessoais, sair do ciclo da violência e dedicação materna, também apareceram como significantes.

Meus planos são que eu espero que meu parceiro mudel esteja [sic] um bom companheiro/ que me ame muito/ fazer planos para o futuro e ser muito feliz/ Eu quero que o meu marido mude/ porque eu gosto muito dele e não quero me separar/Queria um marido bem bom pra eu, ter filhos com ele e não sofrer/Queria que ele fosse uma pessoa melhor/, queria que ele voltasse a ser quando eu me casei/.

É importante constar que as mulheres, em diversos momentos da entrevista, demonstraram dualidade em seus diálogos em contradições. Percebeu-se também que não possuem visão clara do que seja a violência que sofrem e o quanto a permanência no ciclo de violência pode afetar negativamente suas vidas, caracterizando uma situação de extrema vulnerabilidade social.

\section{Considerações finais}

Este estudo indicou que as mulheres vítimas de violência doméstica participantes desta pesquisa sofrem principalmente violência física e psicológica.

As principais representações da violência são objetivadas como frequente, desarmônica e depreciativa. A mulher na maioria das vezes manifesta reações pela violência sofrida com passividade, vergonha, decepção, culpa e sofrimento.

A mulher percebe o homem autor da violência como doente/dupla personalidade, incorrigível ou digno de pena. As principais origens da ação violenta advêm de ciúme, poder e histórico familiar, apontando ancoragens sociais no poder masculino e submissão feminina construída ao longo do tempo.

As principais consequências da violência são o trauma, o desamor e a insensibilidade, provavelmente diminuindo seus índices de qualidade de vida e inserção social.

Em relação às perspectivas para o futuro, foram encontradas perspectivas de mudar o agressor: esperam realização pessoal, esperam sair do ciclo de violência e se dedicarem aos filhos, apontando para representações "mágicas", com pouca percepção da real situação em que vivem, muitas vezes podendo até levar à morte da vítima por seu parceiro.

Este estudo pode ser considerado introdutório para pesquisas futuras. É recomendável que, para maior abrangência do assunto, futuramente seja estudado o fenômeno observando a variável do tempo de relacionamento, tempo de exposição da vítima à violência psicológica ou emocional.

Um diferencial nas características desta pesquisa é a amostra buscada em Delegacia Especializada em Atendimento à Mulher; percebem-se, ainda, poucos estudos no Brasil nessas unidades de atendimento. Destaca-se a abertura e modelo de tratamento diferenciado nessas instituições, o que facilita aspectos metodológicos.

Mais estudos nacionais com a perspectiva aqui abordada poderiam contribuir com a comunidade científica e acadêmica no sentido de produzir melhores e maiores conhecimentos da subjetivação do fenômeno da violência doméstica contra a mulher. Sendo assim, esses novos achados poderiam fornecer novas possibilidades de intervenções.

Assim, estudar essa perspectiva a partir desta ótica é importante não somente no nível de conhecimento e exploração do fenômeno, mas também no que seus resultados e intervenções possam contribuir para minimizar o sofrimento psíquico da mulher.

Para fazer realmente frente à violência doméstica é necessário dar continuidade à integração das unidades de proteção à mulher, maior divulgação nos meios de comunicação com o intuito de prevenir a violência e promover a saúde da mulher, para que ela se sinta apoiada e encontre equipe multiprofissional competente e integrada que lhe ajude a sair do ciclo de violência.

Conforme traz Gadoni-Costa e Dell'Aglio (2010), uma rede capacitada, que realmente funcione como uma engrenagem, tende a fortalecer as instituições 
envolvidas no processo e possibilita que as conquistas recentes no enfrentamento da violência se consolidem.

\section{Referências}

Almeida, T. M. C. \& Bandeira, L. (2006). A violência contra as mulheres: um problema coletivo e persistente. In E. Leocádio \& M. Libardoni (Orgs.), O desafio de construir redes de atenção às mulheres em situação de violência (pp. 19-43). Brasília: Agende.

Alves, A. M. \& Coura, P. F. (2001). Avaliação das Ações de Atenção às mulheres sob violência no espaço familiar, atendidas no centro de apoio a mulher (Belo Horizonte), entre 1996 e 1998. Ciência \& Saúde Coletiva, 6(1), 243-257.

Bardin, L. (2002). Análise de conteúdo. Lisboa: Edições 70.

Carneiro, S. (2003). Mulheres negras, violência e pobreza. In Secretaria de Políticas para as Mulheres, Diálogos sobre violência doméstica e de gênero: construindo políticas para as mulheres (pp. 11-17). Brasília, DF: Secretaria de Políticas para as Mulheres.

Côrtes, G. R. (2012). Violência doméstica: centro de referência da mulher "Heleieth Saffioti". Estudos de Sociologia, 17(32), 149-168.

Dantas-Berger, S. M. \& Giffin, K. (2005). A violência nas relações de conjugalidade: invisibilidade e banalização da violência sexual? Cadernos de Saúde Pública, 21(2), 417-425.

Debert, G. G. \& Oliveira, M. B. (2007). Os modelos conciliatórios de solução de conflitos e a "violência doméstica". Cadernos Pagu, 29, 305-337.

Fundação Perseu Abramo. (2001). Pesquisas de opinião: a mulher brasileira nos espaços público e privado. Acesso em 3 de março, 2012, em http://www.fpa.org.br/o-que-fazemos/ pesquisas-de-opiniao-publica/pesquisas-realizadas/mulher-brasileira-nos-espacos-public

Gadoni-Costa, L. M. \& Dell'Aglio, D. D. (2010). Mulheres em situação de violência doméstica: vitimização e coping. Interinstitucional de Psicologia, 2(2), 151 - 159.

Galvão, E. F. \& Andrade, S. M. (2004). Violência contra mulher: análise de casos atendidos em serviço de atenção á mulher no município do Sul do Brasil. Saúde e Sociedade, Londrina, 13, 89-99.

Goleman, D. (2003). Mentiras essenciais, verdades simples: a psicologia da auto-ilusão. Rio de Janeiro: Rocco.

Januário, I. S. et al. (2010). Violência doméstica contra a mulher: diretrizes legais para a assistência de enfermagem. In Congresso Brasileiro dos Conselhos de Enfermagem, 13. Acesso em 24 de outubro, 2011, em http://189.75.118.67/ CBCENF/sistemainscricoes/arquivosTrabalhos/I19725. E8.T3054.D4AP.pdf

Lei n. 11.340. (2006). Lei Maria da Penha. Brasília, DF: Presidência da República.

Medeiros, H. L. V. \& Sougey, E. B. (2010). Distorções do pensamento em pacientes deprimidos: freqüência e tipos. Jornal Brasileiro de Psiquiatria, 59(1), 28-33.

Monteiro, C. F. S. \& Souza, I. E. O. (2007). Vivência da violência conjugal: fatos do cotidiano. Psicologia \& Sociedade, 16(1), 26-31.

Moscovici, S. (2003). Representações sociais e sociedades: a contribuição de Serge Moscovici. Acesso em 15 de ju- nho, 2010, em http://www.scielo.br/pdf/rbcsoc/v19n55/ a14v1955.pdf

Oliveira, E. M. et al. (2005). Atendimento às mulheres vítimas de violência sexual: um estudo qualitativo. Saúde Pública, 39(3), 376-382.

Pequeno, M. J. P. (2007). Direitos Humanos e Violência. Acesso em 08 de junho, 2010, em http: //www.colegiointegral.com. br/EM/AULAS/2ano/SOC-violencia.ppt

Ribeiro, C. G. \& Coutinho, M. L. L. (2011). Representações sociais de mulheres vítimas de violência doméstica na cidade de João Pessoa-PB. Psicologia e Saúde, 3(1), 52-59.

Sagot, M. (2007). A rota crítica da violência intrafamiliar em países latino-americanos. In S. N. Meneghel (Org.), Rotas críticas: mulheres enfrentando a violência (pp. 23-50). São Leopoldo, RS: Editora Unisinos.

Saffiotti, H. (2001). Contribuições feministas para o estudo da violência de gênero. Cadernos Pagu, 16,115-136.

Schraiber, L. B. et al., (2007). Prevalência da violência contra a mulher por parceiro íntimo em regiões do Brasil. Saúde Pública, 41(5), 797-807.

Soares, V. (2004). O feminismo e o machismo na percepção das mulheres brasileiras. In G. Venturi, M. Recamán, \& S. Oliveira (Orgs.), A mulher brasileira nos espaços público e privado (pp. 161-182). São Paulo: Fundação Perseu Abramo.

Villela, W. (2008). Mulher, violência e AIDS: explorando interfaces. In A. Nilo (Org.), Mulher, violência e AIDS (pp. 107-126). Recife: Gestos.

Zuma, C. E. (2005). Em busca de uma rede comunitária para a prevenção da violência na família. In Anais do III Congresso Brasileiro de Terapia Comunitária. Fortaleza. Acesso em 29 de junho, 2012, em http://www.noos.org.br/acervo/ Embuscadeumaredecomunitariaparaaprevencaodaviolencianafamilia.pdf

Recebido em: 31/08/2010

Revisão em: 10/11/2011

Aceite em: 30/04/2012

Denire Holanda da Fonseca é Psicóloga e Pesquisadora do Centro Universitário de João Pessoa-UNIPÊ.

Endereço: Rua Malaquias Timóteo de Souza, 110. Ernesto Geisel. João Pessoa/PB, Brasil. CEP 58075-692. Email: denireholf@hotmail.com

Cristiane Galvão Ribeiro é Professora Doutora do Centro Universitário de João Pessoa - UNIPÊ. Email: cristianegr@ig.com.br

Noêmia Soares Barbosa Leal é Psicóloga e Pesquisadora do Centro Universitário de João Pessoa - UNIPÊ. Email: noemia.barbosa@hotmail.com

\section{Como citar:}

Fonseca, D. H., Ribeiro, C. G., \& Leal, N. S. B. (2012). Violência doméstica contra a mulher: realidades e representações sociais. Psicologia \& Sociedade, 24(2), 307-314. 